\title{
Layanan Purna Jual pada Produk Otomotif
}

\author{
Fakultas Kewirausahaan, Universitas Garut \\ Jalan Jati 42 B Garut, 44151, Indonesia \\ Solihat_asri@yahoo.co.id
}

\begin{abstract}
Abstrak - Tujuan penelitian ini adalah untuk menganalisis layanan purna jual pada produk otomotif. Desain penelitian ini adalah cross sectional, menggunakan pendekatan deskriptif dengan metode explanatory survei. Unit analisis konsumen sebanyak 51 orang. Pengumpulan data dengan menggunakan kuesioner. Teknik analisis yang digunakan adalah teknik deskriptif dengan menggunakan distribusi frekuensi. Berdasarkan hasil penelitian menggunakan analisis deskriptif, didapatkan hasil bahwa layanan purna jual berkatagori baik. Perbedaan penelitian ini dengan penelitian sebelumnya adalah terletak pada variabel independen, yaitu layanan purna jual pada produk otomotif, serta menggunakan teori atau referensi yang berbeda dengan peneliti sebelumnya.
\end{abstract}

Kata Kunci- Layanan Purna Jual, Produk Otomotif.

\section{PENDAHULUAN}

Layanan purna jual merupakan layanan yang diberikan oleh perusahaan yang bertujuan untuk menjaga hubungan baik dengan pelanggan, degan cara memperbaiki kerusakan pada produk, membantu pelanggan untuk merawat produk yang telah di beli, dan membantu pelanggan ketika ada masalah dengan produk, Layanan purna jual merupakan salah satu produk tambahan yang diberikan oleh perusahaan yang bertujuan untuk meningkatkan kepercayaan dan kepuasan pelanggan terhadap perusahaan yang dengan harapan pelanggan akan membeli kembali di masa yang akan datang, layanan purna jual sangatlah diperhatikan di berbagai industry salah satunya di industry otomotif, ketika pelanggan telah membeli suatu kendaraan pelanggan tidak hanya melihat kualitas dari produknya saja tetapi pelangga juga memperhatikan bagaimana cara perawatan dari kendaraan tersebut, apakah perawatan yang dilakukan sulit atau tidak, kemudian pelanggan pun memperhatikan ketersediaan sparepart dari kendaraan tersebut apakah sparepartnya mahal dan sulit dicari atau tidak, kemudian ketika pelanggan akan melakukan perbaikan kendaraanya apakah bengkel yang tersedia banyak dan mudah di cari atau tidak, ketika semua itu terpenuhi maka niatan pelanggan untuk membeli produk tersebut di kemuadian hari akan semakin tinggi.
Layanan purna jualmerupakan kegiatan yang dilakukan setelah pelanggan membeli produk (Tavakoli, Feyz Arefi, Heidari, \& Mirjafari, 2016) dengan adanya layanan purna jualmaka akan meningkatkan kepuasan pelanggan karena dengan adanya layanan purna jualmaka pelanggan akan merasa tenang ketika memiliki permasalahan terhadap produk yang telah dia beli, pelanggan dapat menghubungi layanan customers support untuk membantu permasalahan yang terjadi,(Cavalieri, Gaiardelli, \& Ierace, 2007). Salah satu industry yang sangat mementingkan layanan purna jualadalah industry otomotif dikarenakan produk yang mereka buat dapat bertahan dengan jangka yang lama, maka dari itu sangat penting bagi produsen untuk selalu menjaga kualitas dan kehandalan produknya meskipun produknya telah di serahkan ke konsumen (Ehinlanwo \& Zairi, 1996), dengan cara melakukan perbaikan dan penggantian sparepart yang telah habis masa pakainya secara berkala terhadap kendaraan yang telah dibeli oleh konsumen.

\section{METODE}

Layanan purna jualadalah rangkaian kegiatan yang terjadi setelah pembelian produk untuk mendukung pelanggan dalam menggunakan dan memperbaiki barang (Tavakoli et al., 2016). Layanan purna jualmerupakan layanan tanbahan yang kepada konsumen yang dapat membangun hubungan yang 
baik dan tahan lama dengan pelanggan (Philip Kotler \& Armstrong, 2014). layanan purna jual merupakan pelayanan yang diberikan kepada konsumen setelah produk diterima (Chaniotakis, Lymperopoulos, Rigopoulou, \& Siomkos, 2008). Menurut (Cavalieri et al., 2007) after sales adalah pelayanan yang terjadi setelah pembelian produk yang ditujukan untuk membantu dalam penggunaan dan memperbaiki masalah produk. Sementara menurut (Ehinlanwo \& Zairi, 1996) layanan purna jual merupakan kegiatan yang diharapkan untuk menjaga kualitas dan kehandalan produk, dilakukan setelah pelanggan menerima produk bertujuan untuk memastikan kepuasan pelanggan. Layanan purna jual ini terdiri dari pengiriman ke pelanggan, instalasi, nomor keluahan pelanggan, layanan perbaikan, dan bahkan proses daur ulang (Chaniotakis et al., 2008).

Menurut (Koskela, 2002) layanan purna jual adalah suatu layanan pemeliharaan yang bertujuan untuk menjaga kelangsungan hidup suatu produk. Layanan purna jual membuat pelanggan merasa percaya bahwa produk yang mereka beli memiliki kualitas baik, mereka tidak lagi mengkhawatirkan bagaimana jika barang yang mereka beli rusak dan dimana tempat untuk mengklaim garansi sebab semua itu dapat dilakukan di jaringan after sale, maka dari itu layanan purna jualdapat meningkatkan kepuasan pelanggan (Xu, Blankson, \& Prybutok, 2017) . Pelanggan yang telah merasa percaya akan kembali membeli produk di perusahaan tersebut. Pernyataan di atas maka dapat dikatakan bahwa after sale serfice adalah layanan yang diberikan oleh perusahaan kepada pelangganya untuk menjaga kualitas dan kehandalan produknya setelah pelanggan menerima produknya.

Menurut (Philip Kotler \& Armstrong, 2014) layanan purna jual memiliki empat dimensi diantaranya adalah

1. Guarantee (Garansi). Garansi diberikan kepada pelanggan agar pelanggan menjadi yakin bahwa produk yang mereka terima itu memiliki kualitas yang baik bebas dari kerusakan yang di sebabkan kesalahan dalam pengerjaan atau penggunaan bahan yang berkualitas buruk, yang berlaku dalam jangka waktu yang telah di tentukan.

2. Sparepart (Sukucadang), peran suku cadang ini sagat penting bagi konsumen karena ketika salah satu komponen produk sudah rusak maka diperlukan komponen yang baru dan ketika komponen yang baru itu tidak ada maka kehandalan produk tersebut akan menurun atau bahkan produk tersebut tidak biasa di pakai kembali.

3. Maintanace and repair (Pemeliharaan dan perbaikan), layanan ini dibutuhkan ketika sebuah produk memiliki jangka waktu pakai yang cukup lama yang dan membutuhkan perawatan berkala untuk menjaga kehandalan dari produk tersebut dan untuk memperbaiki segala kerusakan yang dialami oleh peroduk tersebut ketika masa pemakaian.

4. Facility and equipment (Fasilitas dan Peralatan), fasilitas dan perlengkapan yang memadai dapat membantu petugas untuk menyelesaikan masalah yang terjadi dengan produk tersebut, semakin canggih fasilitas dan perlengkapan maka semakin mudah petugas memperbaiki masalah yang ada di produk tersebut

Sementara menurut (Koskela, 2002) layanan purna jualmemiliki empat dimensi yaitu :

1. Maintenance, atau pemeliharaan adalah sebuah layanan yang ditujukan untuk menjaga kualitas produk ketika telah berada di tangan pelanggan, ketika pelanggan telah melakukan pemeliharaan maka kualitas produk akan semakin terjaga dan dapat memperpanjang usia pakai suatu produk.

2. Preventive maintenance, atau pemeliharaan pencegahan berguna untuk mengurangi kegagalan peralatan dan mengurangi resiko kerusakan produk, degan adanya pemeliharaan ini maka pelanggan dapat mengetahui kapan kerusakan produk terjadi dan dapat mencegah kerusakan tersebut.

3. After sale support, atau dukungan layanan purna jual berguna agar pelanggan mendapatkan pelayanan yang efisien dan mendapatkan suku cadang yang terjangkau.

4. Field service, adalah seorang yang dapat memperbaiki kerusakan produk, memelihara produk dan meningkatkan produk dengan mengedepankan efisiensi agar pelanggan mendapatkan harga yang terbaik.

Menurut (Tavakoli et al., 2016) layanan purna jualmemiliki dimesi 1) installation and storage 2) Maintenance and repair 3) management of end product life. Menurut (Xu et al., 2017) dimensi after sale ervice adalah 1) Repair, 2) maintenance, 3) customers care. Sementara menurut (Philip Kotler \& Armstrong, 2014) dimensi afterselae service adalah 1) Maintenace 2) Facility 3) Sparepart. 
III. HASIL DAN PEMBAHASAN

Secara keseluruhan Layanan purna jual (X) yang terdiri dari service maintenance and repair, guarantee, spareparts, dan facility and equipment dapat diketahui kedudukanya berdasarkan skor yang didapat dari rekapitulasi data. Rekapitulasi data pada variabel layanan purna jual(X) dapat dilihat pada tabel 4.8 :

TABEL 4. 1

\section{REKAPITULASI TANGGAPAN KONSUMEN NISSAN DI FACEBOOK MENGENAI AFTER SALE SERVICE}

\begin{tabular}{|c|c|c|c|}
\hline No & Dimensi & Skor & $\%$ \\
\hline 1 & Service Maintanance and Repair & 1.278 & 59,66 \\
\hline 2 & Guarantee & 702 & 65,55 \\
\hline 3 & Spareparts & 949 & 66,46 \\
\hline 4 & Facility and Equipment & 829 & 77,48 \\
\hline & Total Skor & 3.758 & 72,66 \\
\hline
\end{tabular}

Sumber : Hasil pengolahan data 2018

Berasarkan tabel 4.8 dimensi yang mendapatkan nilai tertinggi adalah dimensi facility and equipment dengan persentase sebesar $77,48 \%$ dan skor sebesar 829 ini menunjukan bahwa konsumen merasa fasilitas dan perlengkapan di bengkel resmi Nissan telah baik, selanjutnya indikator yang memiliki nilai terendah adalah service maintanace and repair dengan persentase sebesar $59,66 \%$ dan dengan skor sebesar 1.278. hal ini menunjukan konsumen merasa perawatan mobil Nissan tergolong sulit dan cukup mahal.

Berdasarkan hasil rekapitulasi variabel layanan purna jualdimensi yang mendapatkan nilai tertinggi adalah dimensi facility and equipment dengan persentase sebesar 77,48\% dan skor sebesar 829 ini menunjukan bahwa konsumen merasa fasilitas dan perlengkapan di bengkel resmi Nissan telah baik, selanjutnya indikator yang memiliki nilai terendah adalah service maintanace and repair dengan persentase sebesar $59,66 \%$ dan dengan skor sebesar 1.278. hal ini menunjukan konsumen merasa perawatan mobil Nissan tergolong sulit dan cukup mahal. Kemudian ada beberapa indikator yang jumlah respondent memilih skor terkecil yaitu 1 cukup tinggi adalah indikator Harga sparepart dengan 14 respondent memilih skor 2 kemudian 6 respondent memilih skor 1 dan 13 respondent memilih sko $\mathrm{r} 3$ yang menandakan bahwa Harga dari sparepart Nissan tergolong mahal kemudian pada indikator kemudahan mendapatkan sparepart jumlah respondent yang memilih skor 1 ada 6 orang respondent yang memilih skor 3 ada 10 orang kemudian respondent yang memilih skor 4 ada 13 orang kemudian respondent yang memilih skor 5 ada 10 orang kemudian respondet yang memilih skor 6 ada 8 orang dan respondent yang memilih skor 7 ada 4 orang ini menandakan bahwa distribusi sparepart Nissan tidak merata dikarenakan ada sebagian besar merasa sparepart Nissan tidak terlalu sulit dan tidak terlalu mudah menemukan spareparts Nissan namun sebagian kecil sangat merasa sulit menemukan spareparts Nissan dan sebagian kecil lainya merasa sangat mudah untuk menemukan spareparts Nissan. Kemudian niat respondet untuk membeli kembali produk Nissan akan meningkat bila Nissan lebih mempermudah konsumen untuk menemukan spareparts dan jika lebih banyak motir selain montir pada bengkel resmi Nissan yang dapat memperbaiki mobil Nissan.

\section{KESIMPULAN}

Sebagian Besar penguna Nissan di Facebook menyatakan after sale service yang diberikan Nissan dalam kategori baik hal ini dapat dilihat dari dimensi tertinggi hingga terendah. Dimensi after sale service yang memiliki nilai tertinggi adalah dimensi facility and equipment, sementara dimensiyang memilini nilai teredah adalah dimensi service maintance and repair. Pada dimensi service maintanace and repair ada beberapa indikator yang memiliki skor yang rendah seperti pada indikator biaya maintance mobil Nissan sebagian besar respondent memilih skor dari 4 ke bawah yang dapat disimpulkan bahwa sebagian besar respondent merasa biaya perawatan Mobil Nissan 
mahal biaya perawatan ini termasuk konsumsi bahan bakar, biaya bengkel dan lain-lain . salah satu hal yang harus dilakukan Nissan adalah membuat mobil yang lebih hemat bahan bakar dan memberikan potongan Harga pada bengkel resmi. Kemudian pada indikator banyaknya mekanik selain mekanik di bengkel resmi Nissan yang bisa memperbaiki.

Mekanik yang dapat memperbaiki mobil Nissan sebagian besar respondent memilih skor 4 kebawah yang berarti bahwa mekanik diluar bengkel resmi Nissan masih tergolong sedikit hal yang perlu dilakukan oleh Nissan adalah dengan cara memberikan workshop kepada bengkel-bengkel selain bengkel resmi Nissan tentang bagaimana meperbaiki mobil Nissan yang tepat. Pada dimensi guarantee sebagian besar respondent memberikan nilai pada skor 4 yang berarti respondent merasa pelayanan garansi Nissan pada kategori biasa saja , makadari itu Nissan bisa meningkatkan pelanyanan garasinya agar dapat menjadi salah satu keungglan dari merek tertentu dengan cara Nissan bisa memberikan waktu garansi yang lebih lama dari pada competitor lain. Pada dimensi sparepart terdapat indikator yang memiliki persentase dibawah $60 \%$ yang pertama yaitu indikator kemudahan mendapatkan spareparts Nissan dengan persentase $59,9 \%$ dan respondet memilih hapir di semua pilihan skor yang menandakan bahwa penyebaran sparepart Nissan tidak merata karena ada sebagian respondent yang merasa mudah mendapatkan sparepart Nissan namun sebagian lainya merasa sulit untuk menemukan sparepart Nissan, maka dari itu hal yang perlu dilakukan oleh Nissan adalah dapat mendistribusikan sparepart Nissan lebih baik lagi dengan cara mendistribusikan sparepart Nissan ke kota-kota kecil di Indonesia dan dapat mendistribusikan sparepart kepada toko-toko onderdil yang ada di setiap kota agar konsumen mudah mendapatkan sparepart Nissan, selanjutnya indikator yang meliki nilai persentase terkecil adalah indikator Harga sparepart Nissan denga persentase sebesar $42,30 \%$ yang berarti respondent merasa Harga sparepart Nissan tergolong mahal, maka dari itu Nissan harus dapat menurunkan Harga sparepartnya dengan cara memberikan discount atau membuat sparepart dengan Harga yang lebih murah, Nissan juga bisa bekerja sama dengan merek-merek pembuat sparepart mobil lain untuk membuat onderdil Nissan dengan merek mereka agar konsumen mendapatkan beberapa pilihan ketika akan membeli sparepart. Pada dimensi Kepuasan indikator yang memiliki persentase terendah daripada yang lainya adalah kepuasan dengan after sale service Nissan dengan persentase sebesar $63,58 \%$ yang berarti bahwa respondent merasa kurang puas dengan layanan after sale yang diberikan oleh Nissan, maka hal yang dapat dilakukan oleh Nissan adalah lebih meningkatkan pelayanan purna jualnya dengan cara membrika Harga sparepart yang murah, membuat distribusi sparepart yang efektif agar pelanggan lebih mudah mendapatkan sparepart Nissan .

\section{REFERENSI}

[1] J. Kim and H.-M. Joung, "Psychological underpinnings of luxury brand goods repurchase intentions: Brand-self congruity, emotional attachment, and perceived level of investment made," J. Glob. Sch. Mark. Sci., vol. 9159, no. June, pp. 1-16, 2016.

[2] I. O. Pappas, A. G. Pateli, M. N. Giannakos, and V. Chrissikopoulos, "Moderating effects of online shopping experience on customer satisfaction and repurchase intentions," Int. J. Retail Distrib. Manag., vol. 42, no. 3, pp. 187204, 2014.

[3] H. T. Tsai and H. C. Huang, "Determinants of e-repurchase intentions: An integrative model of quadruple retention drivers," Inf. Manag., vol. 44, no. 3, pp. 231-239, 2007.

[4] S. W. Chou and C. S. Hsu, "Understanding online repurchase intention: social exchange theory and shopping habit," Inf. Syst. E-bus. Manag., vol. 14, no. 1, pp. 19-45, 2016.

[5] J. D. McConnell, "Repeat-Purchase Estimation and the Linear Learning Model," $J$. Mark. Res., vol. 5, no. 3, pp. 304-306, 1968.

[6] D. Gill and B. (Ram) Ramaseshan, "Influences on supplier repurchase selection of UK importers," Mark. Intell. Plan., vol. 25, no. 6, pp. 597-611, 2007.

[7] L. Su, S. R. Swanson, and X. Chen, "The effects of perceived service quality on repurchase intentions and subjective wellbeing of Chinese tourists: The mediating role of relationship quality," Tour. Manag., vol. 52, pp. 82-95, 2016.

[8] P. G. Patterson and R. A. Spreng, "Modelling the relationship between perceived value, satisfaction and repurchase intentions in a business-to-business, services context: an empirical examination," Int. J. Serv. Ind. Manag., vol. 8, no. 5, pp. 414-434, 1997. 
[9] W. Chiu and D. Won, "Consumer-brand relationships in sports products and repurchase intention: An application of the investment model," vol. 17, no. 3, pp. 243-259, 2016.

[10] C. Ennew and J. Devlin, "International Journal of Bank Marketing," Mark. Intell. Plan., vol. 11, no. 6, pp. 8-10, 2015.

[11] A. Y. C. Lam, M. M. Lau, and R. Cheung, "Modelling the Relationship among Green Perceived Value, Green Trust, Satisfaction, and Repurchase Intention of Green Products," Contemp. Manag. Res., vol. 12, no. 1, pp. 4760, 2016.

[12] M. Thanomsub, "Factors Affecting Consumer's Purchase Intention toward Japanese Car in Bangkok," 2014.

[13] N. Sa, A. Kanyan, and M. F. Nazrin, "The Effect of E-WOM on Customer Purchase Intention," vol. 2, no. 1, pp. 73-80, 2016.

[14] P. Aryadhe and N. M. Rastini, "Kualitas Pelayanan, Kualitas Produk dan Citra Merek Terhadap Niat Beli Ulang di PT Agung Toyota Denpasar," vol. 5, no. 9, pp. 56955721, 2016.

[15] A. Z. Arifin and R. S. Subagio, "Kepuasan Pelanggan Untuk Pembelian Mobil Honda," vol. XX, no. 01, pp. 63-81, 2016.

[16] Www.otomotifmagz.com, "penjualan-nissanterus-merosot-3-tahun-terakhi," 2017.

[17] Www.gaikindo.or.id, "domestic-auto-marketby-brand-2013-2014/,” 2015. .
[18] H. Tarofder, Nikhashemi, Azam, "The mediating influence of service failure explanation on customer repurchase intention through customers satisfaction," Int. J. Qual. Serv. Sci., vol. 8, no. 4, pp. 516-535, 2016.

[19] Haemoon and K. Kim, "Customer satisfaction, service quality, and customer value: years 2000-2015," Int. J. Contemp. Hosp. Manag., vol. 29, no. 1, pp. 2-29, 2017.

[20] james F. Engel, R. D. Blackweel, and P. W. Miniard, Consumer Behaviour, Sixth. Chicago: The Dryden Press, 1992.

[21] M. Khan, Consumer Behaviour And Advertising Management. New Delhi: New Age, 2006.

[22] R. Filieri and Z. Lin, "The role of aesthetic, cultural, utilitarian and branding factors in young Chinese consumers' repurchase intention of smartphone brands," Comput. Human Behav., vol. 67, pp. 139-150, 2017.

[23] H. Noel, Consumer behaviour. Lausanne: AVA Publishing SA, 2009.

[24] S. H. Darpito, "Analisis Pengaruh Penyesalan, Nilai Komplain, dan Kepuasan terhadap Niat Pembelian Ulang dengan Niat Menyampaikan Komplain sebagai Intervening Variabel Surpiko Hapsoro Darpito," pp. 1-25, 2009.

[25] P. Kotler and G. Armstrong, Principles of Marketing, 15E ed. New jersey: Pearson, 2014. 